\title{
Mobile Technology: Binding Social and Cloud into a New Enterprise Applications Platform
}

\author{
Luminita HURBEAN ${ }^{1}$, Doina FOTACHE ${ }^{2}$ \\ ${ }^{1}$ West University of Timisoara, Romania \\ 2"Al. I. Cuza" University of Iasi, Romania \\ luminita.hurbean@feaa.uvt.ro \\ doina.fotache@feaa.uaic.ro
}

Nowadays, the IT industry is revolving around the build-out and adoption of a new platform, characterized by mobility, cloud-based application and service delivery, and value-generating overlays of social business and pervasive analytics. The paper explores the convergence of mobile, cloud, and social, as well as the effects for the enterprise and the emergence of the new enterprise application platforms. In the beginning we set the stage, while showing the expansion of the mobile, cloud, and social in the business information system, as they were found in the literature. We then look over the IT trends, especially the consumerization of IT, as reasons and basis for the information systems embracing of mobile. Afterwards, we present a mobility roadmap for the enterprise and illustrate the reconfiguration of the enterprise application platform.

Keywords: Mobile Technology, Cloud Computing, Social Networking, Enterprise Applications

1 Introduction

The changes set in motion by the Internet and the web technologies are irreversible and have strong impact, but it will take more time to diffuse through organizations. Migrating from old to new ways of doing business has always been a continuous, open-ended process [1].

We have witnessed so many IT trends in the last 20 years and we believe that none was as pervasive as mobile technology. The ability to access any content, on any device over any network in any location, is becoming a reality. While the whole IT budget is either same or declining, the one bright point is mobility. According to some studies, in 2011 and 2012, mobility budgets were $40 \%$ larger than in 2010 [2]. Organizations consider the enlargement of the number of employees with smartphones (from less than $50 \%$ in 2010 to over $70 \%$ by 2013 ), which triggers the raise of the number of devices requiring support (Apple, Android-based and RIM devices, as well as tablets) and the associated costs. The new environment demands to deliver services to employees in a mobile cloud computing model.
Social networking evolved massively in the last few years, at an incredible pace and became the preferred way of interaction, sharing and collaboration between people. Particularly, the last few years repositioned the interaction and sharing on the mobile devices. According to some studies, $60 \%$ of Facebook updates are from mobile devices and around $80 \%$ of staff members are using their phones and other devices for both work and personal purposes and these figures must prompt the managers' interest and reconfigure the enterprise information architecture [3]. Passing over the social networks, other social technologies like blogs, wikis, emeetings, instant messaging or document sharing are noteworthy instruments for employees to collaborate and come upon innovation.

From the business point of view, the wireless access ubiquity, the proliferation of mobile devices and the urgency to keep business moving have brought the mobile technology in the enterprise information system. From the users and consumers point of view, their real-time, continuous collaboration and their new behavior combined with the first two arguments have brought the social in the enter- 
prise information system. If we add a fourth ingredient - the cloud - we obtain the entire representation of enterprise mobility. Today the state of the art in business technology is repositioning in "the third platform", which includes mobile devices and applications; the cloud services; the explosive data growth and a new generation of solutions. Let us mention that the first two platforms were: (1) mainframes and terminals and (2) the client-server model supported by the PC.
This blend of social capabilities, mobile technology and cloud computing materialize into a new platform that forms the basis of a new information system [4]. The interdependency is illustrated in Figure 1, where we also considered the position and the role of the enterprise applications. Subsequently, we aim to discuss the concepts and point out the influence of the mentioned key technologies and then consider the estimated transformation and a roadmap for the enterprise mobility.

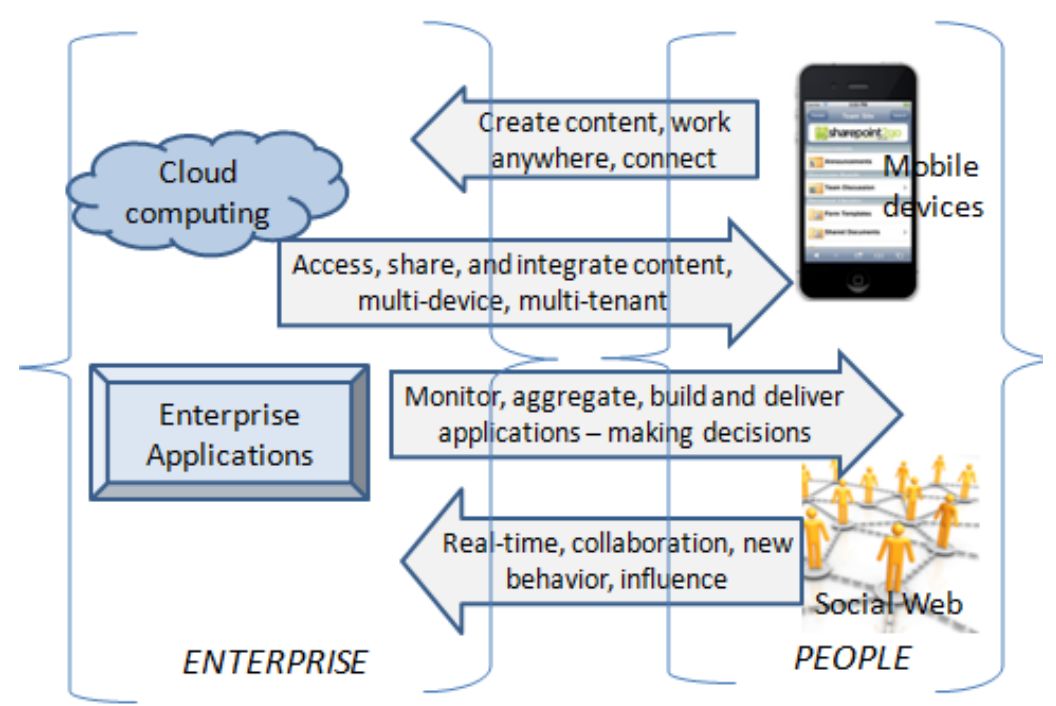

Fig. 1. The blend of cloud, mobile and social and the enterprise applications

\section{Literature Review}

The Information Technology landscape is at the dawn of a radical change in response to a new set of business realities. The nature of work (how and where it gets done), the expectations of a new generation of workers (accustomed to an "always-on/always connected" electronic lifestyle), and emerging business models that challenge traditional concepts of IT cost and time-to-value are driving the change. In response, mobile computing, cloud and Software-as-a-Service (SaaS) delivery and social business collaboration technologies are rapidly gaining momentum in the enterprise information systems.

Mobile computing continues to emerge as a subject of substantial industrial and academic interest and the meaning and scope of mobile computing continues to be debated. This area is covered in the literature with books defined as "complete reference guide" or books which focus on a specific mobile subject.

Series like Advanced in Computers, which is the oldest series still being published, covers the developments in mobile in a special volume The Internet and Mobile Technology (editor M. Zelkowitz, Academic Press, 2011). Like this, many other volumes are discussing the mobile technology in general, or discuss a particular subject like hardware and/or software (MacRae K., Haynes Mobile Technology Manual, Haynes Publishing PLC, 2005, Agrawal D. and Zeng Q.A., Introduction to Wireless and Mobile Systems, Cengage Learning, 2010, Zheng P. and Ni L., Smart Phone and Next Generation Mobile Computing, Morgan Kaufmann, 2010 or Talukder A., Mobile Computing, Tata McGraw-Hill Education, 2010). Security is 
also an issue related to mobile devices and applications as well (e.g. Dwivedi H., Mobile Application Security, McGraw-Hill Education, 2010).

Mobile Application Development is a popular topic these days, when tons of mobile apps are released and available tools and resources are expanding. Experienced professionals share their knowledge mostly online (sites, blogs, forums, and other forms of sharing) but there are books as well: Roebuck K., Mobile Application Development: Highimpact Strategies - What You Need to Know (Lightning Source Inc, 2011), Duraphe K. et al, Customised Mobile Application Development (Lambert Academic Publishing, 2010), Lee V. et al, Mobile applications: architecture, design, and development (Pearson Education, 2004).

Above and beyond the technical aspects, for the enterprise information system administrator and manager it is essential to know how mobile technology fits into it. Discussions on how to introduce mobile into the enterprise landscape need to go beyond the technology and help create the strategy; one very interesting book is Pearson A., The Mobile Revolution (Lulu.com, 2011).

Mobile technologies enable us to work and connect 24/7, anytime, anywhere, changing the way people interact and cooperate with each other. What are the social and economic implications of this technological revolution and the impact for companies? The subject is not new, as we have found references that are older than 10 years ago, and it still is the source of debate for many books: Ling R., The Mobile Connection: The Cell Phone's Impact on Society (Morgan Kaufmann, 2004), New tech, new ties: how mobile communication is reshaping social cohesion (MIT Press, 2008), Brown B., Green N., Harper R., Wireless world: social and interactional aspects of the mobile age (Springer, 2002), Hanson J., Twenty-four Seven (Greenwood Publishing Group, 2007).

Cloud computing has became very attractive for companies in the last five years, therefore the literature is very generous, offering a lot of articles and books, most of them dedicated to managers in order to understand the concept and how can it be employed. We cite here the books: Velte A., Velte T., Elsenpeter R., Cloud Computing. A Practical Approach (McGraw Hill, 2010), Marks E., Lozano B., Executive's Guide to Cloud Computing (John Wiley \& Sons, 2010), Rhoton J., Cloud Computing Explained: Implementation Handbook for Enterprises (Recursive Press, 2010), Van Der Molen F., Get Ready for Cloud Computing (Van Haren Publishing, 2010) and just mention the long list of articles, images and videos available on the web. However, the cloud is in the first place a technical concept, a field where specialists have to operate. The cloud based architecture and computing environment are presented in books like Rittinghouse J. and Ransome J., Cloud Computing: Implementation, Management and Security (CRC Press, 2010), Buyya R., Broberg J., Goscinski A., Cloud Computing: Principles and Paradigms (John Wiley \& Sons, 2010) or O'Reiley J., Cloud Application Architectures: Building Applications and Infrastructure in the Cloud (O'Reiley Press, 2009). We might also mention the Handbook of Cloud Computing, a solid 600 pages book published by Springer in 2010 [5].

They say that cloud computing is the next stage of the Internet computing model, one in which organizations will consume services, not technologies. Among the interesting books we mention: Linthicum D., Cloud Computing and SOA Convergence in Your Enterprise: A Step-by-Step Guide (AddisonWesley, 2009) and Finger P., Dot Cloud: The 21st Century Business Platform Built on Cloud Computing (Meghan-Kiffer Press, 2009). We also find very interesting the subject of collaborative platforms, which bring together technologies and we want to mention the book of Miller M., Cloud Computing: Web-Based Applications That Change the Way You Work and Collaborate Online (Que Publishing, 2009).

Last, but not least, the cloud comes with critical security implications, concerns which are described in all books that discuss about 
cloud computing. This topic is a subject of substantial interest and many experts have published articles that address different aspects of security in the cloud computing environments, like Carlin and Kurran, Jamil and Zaki, Liu J. or Trivedi and Pasley, to mention but a few [6]. We might also mention volumes like Mather T., Kumaraswamy S., Latif S., Cloud Security and Privacy: An Enterprise Perspective on Risks and Compliance (O'Reiley Press, 2009).

Finally, the immense interest on cloud computing reshaped the Web landscape and we have a lot of options when browsing on the Internet. Some of the relevant websites are: www.cloudsecurityalliance.org/, http://opencloudconsortium.org/, www.cloudaudit.org/,

www.opencloudmanifesto.org/, www.cloudstandards.org/wiki/, http://cloudsecurity.org/.

Social software and social networking have generated an unprecedented level of employee and consumer participation. A 2008 book, proposes the term Enterprise 2.0, defining a company which embraces these technologies as part of its information and knowledge management strategy (Cook N., Enterprise 2.0: How Social Software Will Change the Future of Work, Gower Publishing, 2008).

Many other books emphasize the social topics, some of them indicating how to successfully use social media to rebuild the businesses and the brands (Lewis M., Social Media Leadership: How to Get off the Bench and into the Game, Leigh Walker, 2011).

In relation to our research team, we also found books which analyze social technology in the business arena, including planning and goal-setting, assembling a social tech team, integrating social tech within the enterprise information platform and we particularly like Klososky S., Enterprise Social Technologies: Helping Organizations Harness the Power of Social Media, Social Networking, Social Relevance (Greenleaf Book Group, 2011).

Social software has already supplanted email as the communication and collaboration method of choice for the rising generation of corporate workers. How can a company adopt social media intelligently, effectively, and securely in order to support collaboration? Some books provide a practical understanding of the strategies behind social media lend to material benefits: Mickler R, Simple Social Media (CreateSpace, 2011), Howard T., Design to Thrive: Creating Social Networks and Online Communities that Last (Morgan Kaufmann, 2009), Postman J., SocialCorp: Social Media Goes Corporate (Peachpit Press, 2009) etc.

\section{Key Technology Trends and Their Con- sequences for the Enterprise Applications Landscape}

As we already mentioned, the current landscape of the business information system is under the influence of mobility and one main generator was the consumerization of IT.

Usually, adoption of IT was started by army or other government institutions followed by the business organizations. Those technologies were not many (low volume) and were expensive. Only over a consistent period of time, costs went down and technologies became affordable for the individual consumer. At present the direction of technology absorption has reversed because many of the most modern technologies are adopted by the individual consumer first. The trend was named consumerization of IT.

The number of active mobile applications users is currently over 1 billion and inflating the Yankee Group estimates that the number of users will surpass 2 billion in a couple of years [7]. Strategy Analytics, a reliable forecaster for digital technology adoption, estimates that the total number of apps downloaded reached 32 billion in 2012 from 23 billion in 2011 (cited in [8]).

IDC estimates that there are more than 1.2 million apps available for the various mobile operating systems such as iOS and Android in comparison to only 75,000 for PCs. Even if only 100,000 of these are useful in the enterprise, that's more mobile apps that PCbased apps.

A 2011 IDC study [9] reveals that the percent of employees that are using their own devices to access business applications has grown 
from $30 \%$ in 2010 at $40 \%$ in 2011 . Employees are demanding to be able to use their own devices (smartphones and tablets) to access the enterprise information system and perform their business tasks (in this context a new acronym was born: BYOD, standing for Bring Your Own Device). Obviously, these devices are creating many severe security problems for enterprises [10], but the forces of consumerization cannot be stopped. The meeting point of the mobility track which targets collaboration with the enterprise information system which pursues the integration is the enterprise mobile platform, as shown in Figure 2.

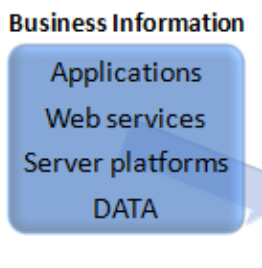

INTEGRATION
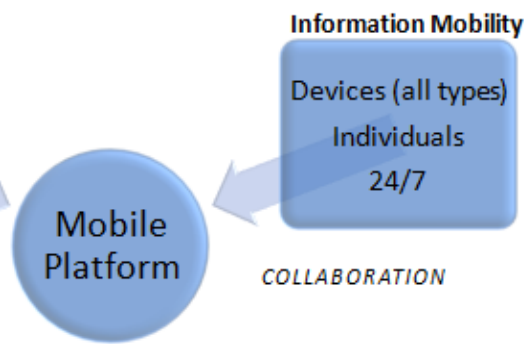

Fig. 2. The enterprise mobile platform

4 Enterprise Mobility Based On Cloud and Embedding Social - A Roadmap

Enterprise mobility permits end users to unchain from their desks and PCs. These days, as we showed in the beginning, more employees do work outside the office with smartphones and tablets, sharing and accessing data via cloud services. Enterprise mobility improves employee productivity on one side but creates security risks on the other (dark) side. Due to these tendencies, IT department needs to keep up with the latest mobile computing evolutions: devices, oper- ating systems, mobile apps, tools and platforms, in order to manage, secure and make the most of them. The most frequent motives to invest in mobile solutions are related to customers (improving responsiveness and fostering collaboration), operational efficiency (business processes transformation), and last, but not least, employees (providing mobile access, improving employee productivity, fostering collaboration, improving worklife balance, and even supporting employeepurchased mobile devices for business processes), as shown in Figure 3.

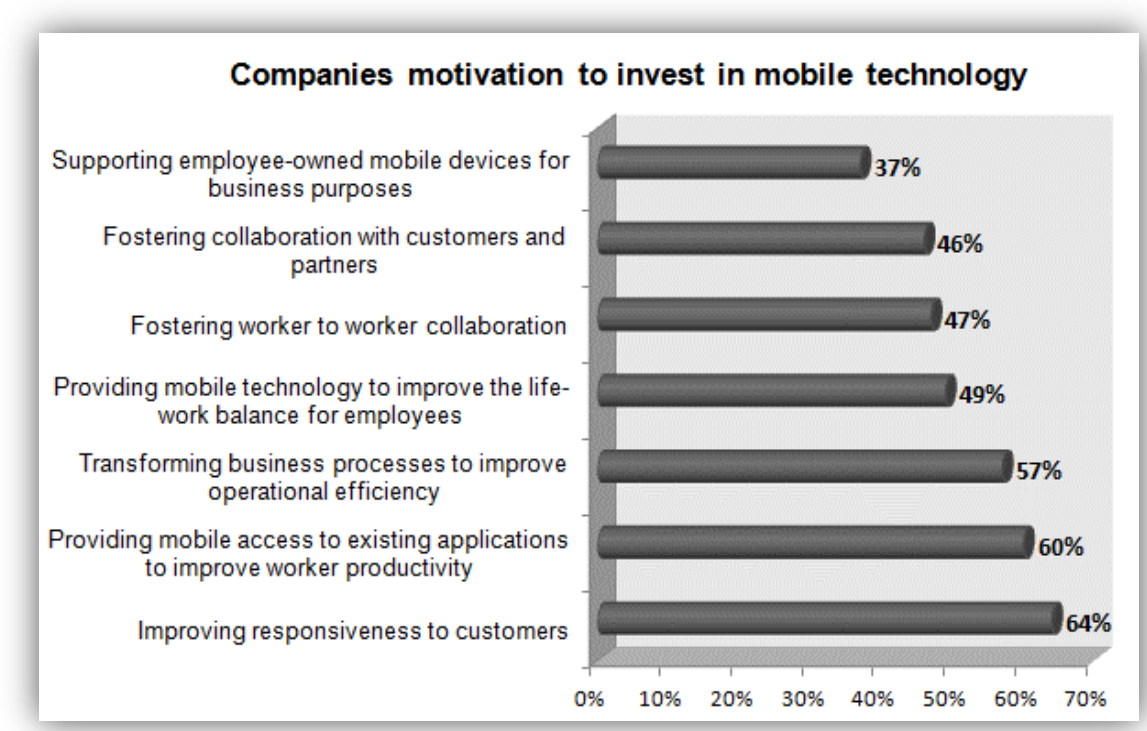

Fig. 3. Companies motives to invest in mobile solutions

(source: Yankee Group, 2012 US ITDM Mobile and Connected Devices Survey [11]) 
There are seven phases in a mobile IT project:

a. Alignment of the project with the enterprise mobility strategy. An enterprise must have a long term mobility strategic vision, coupled with a short to mid-term tactical approach meant to link the rapid technology changes with the business goals and the users' requirements [12].

b. User workflow analysis. Like any other application development, a good process analysis is placed in the beginning and it targets the identification of requirements. Users play an important role, as in every requirements specification phase of a project.

c. Mobile platform selection. There are two types of platforms to be selected: Mobile Enterprise Application Platform (MEAP) and Mobile Device Management Platform (MDMP). They must provide tools for managing the applications, users and devices, on one side and instruments for building integrated mobile applications with the operational workflows across the enterprise, on the other side [13]. It is a difficult phase because there are many available products, offering different capabilities. Many of them are offering an integrated development studio which accelerates the mobile application development (used effectively in phase 6). Even if at the moment only the MDM platform is necessary, it is recommendable to select the MEAP, as they should match.

d. Device and operating system selection. This is another problematical phase, due to the diversity of options and the employees' pressure to use their own mobile devices. From the technical point of view, the first choice seems to be the most popular devices and OSs but this is more appropriate when developing for individual consumers. For enterprise applications, technical criteria should be analyzed, as well as users' related issues. The purpose is to ensure a proper management of the devices (staging, monitoring, malfunctioning, etc.) in correlation with their lifecycle. The ideal would be to have a device-agnostic mobile application, which is compatible with most operating systems and may also work on different types of devices, including notebooks, tablet PCs or smartphones [14].

e. Back-end integration. It is an essential phase in the economy of the project. A project might fail if the back-end integration doesn't work. The most common used platform is EAI (Enterprise Application Integration) which is a middleware layer in the enterprise information architecture. This middleware layer aggregates data from the back-end (ERP) system and intelligently distributes in the appropriate format to the mobile devices. Having the greater than before number of mobile applications, a new middleware layer is responsible for back-end integration: the MEAP.

f. Mobile application development. Lots of mobile apps are developed, but so many of them are poorly designed and fail to deliver functionality. A good mobile application is highly usable, has a proper and accepted way to access information, has a well-designed user interface, and is responsive. The three basic requirements are: user-friendliness, response time and switch between applications, look and feel. Ideally, whether the mobile devices are company-owned or employee-owned, mobile applications should be written once and deployed to many devices via a mobile cloud model (BaaS).

g. Mobile application deployment. If the development phase produced a userfriendly and usable application, the deployment will succeed. This phase also includes a change management process. The accomplishment of this phase is substantially dependable on the end-users, which should be involved from the early phases because they may contribute to the development process and the training programs.

A representation for the enterprise mobile platform is proposed in Figure 5. 


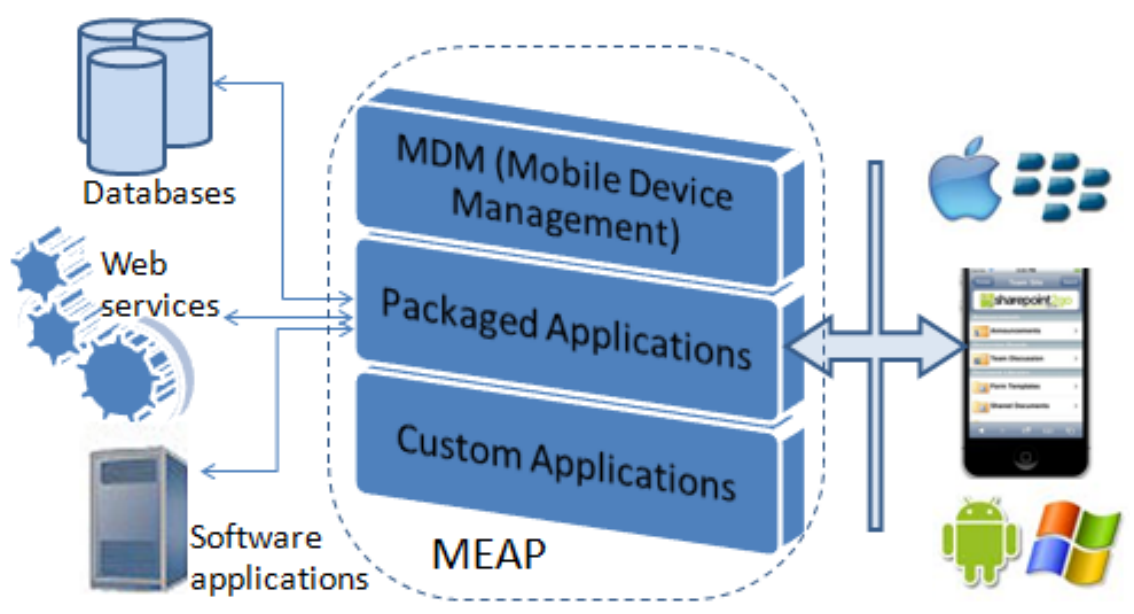

Fig. 5. The enterprise mobile platform

Mobile applications utilize largely the cloud either for computing or for storage. Cloud computing provides services (notifications, location services, photo collection, advertising etc.) and capabilities (e.g. social integration) that go together with the mobile apps on the device. The cloud also cares for the mobile infrastructure: both MEAP and MDM systems may be deployed as virtual images in the cloud.

Not as well known as Software as a Service (SaaS), Infrastructure as a Service (IaaS) or
Platform as a Service (PaaS), the Back-End as a Service (BaaS) ecosystem has quickly evolved. BaaS is a model for providing developers with a way to link their mobile applications to back-end cloud storage while also offering features such as user management, file storage and sharing, push notifications, and integration with social networking services [15]. Table 1 summarizes the main aspects that are necessitating attention when analyzing the fusion between mobile, social and cloud into an IT platform.

Table 1. The main aspects

\begin{tabular}{|l|l|}
\hline Mobile & - MEAP and MDMP choice \\
& $\begin{array}{l}\text { - Match the MEAP with the BaaS system } \\
\text { - Ensure privacy and protect personal information } \\
\text { - Generate appropriate data to deliver business value (context of location, be- } \\
\text { haviour, activity) }\end{array}$ \\
\hline Social & $\begin{array}{l}\text { - Social training and education in order to drive social integration } \\
\text { - Reconsider the business goals } \\
\text { - Take data from the social interaction into the enterprise database } \\
\text { - Tie the social platform into a cloud based system }\end{array}$ \\
\hline Cloud & $\begin{array}{l}\text { - Choose a service model (IaaS, PaaS, SaaS) } \\
\text { - Define specific needs (speed of development, test, deployment etc.) } \\
\text { - Choose a deployment model (private, public hybrid) } \\
\text { - Deal with the security issues } \\
\text { - Analyze the vendor dependency }\end{array}$ \\
\hline
\end{tabular}

We believe that the proliferation of smart devices and mobile cloud apps in the enterprise is driving the constant reconsideration of the enterprise mobility strategy. Based on the strategy, evaluation is performed and then the solution turns out, following the well-known sequence "develop - integrate - deploy manage" (presented earlier with the seven phases) in a cloud-based environment (see Figure 4). 


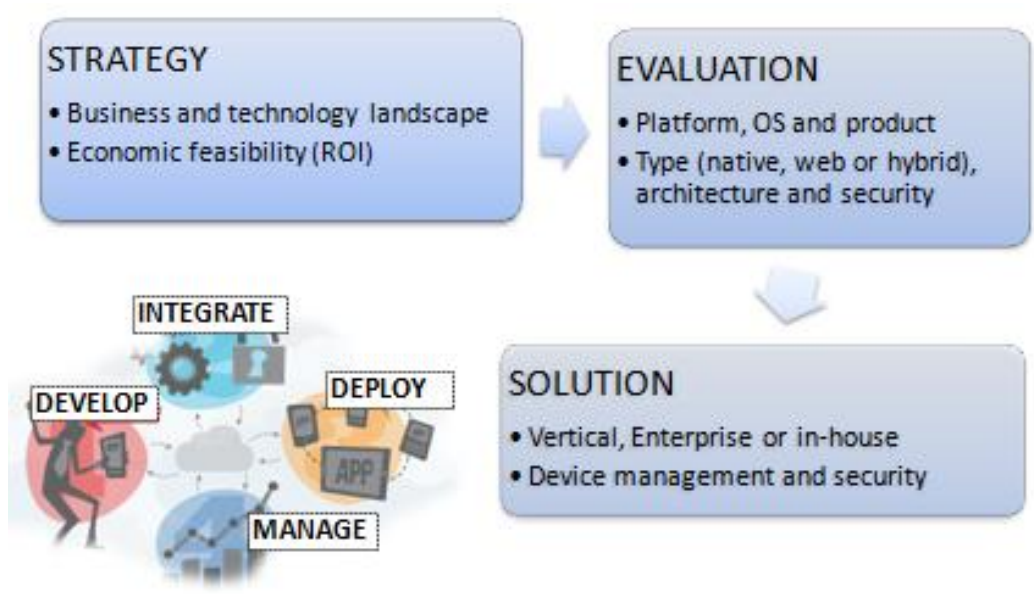

Fig. 4. From enterprise mobility strategy to mobile solution

As many reports indicate, mobile development faces many challenges:

- connectivity to back-end systems and data;

- device diversity and multiple platforms;

- high users' expectations;

- integration with existing development processes [16].

A reliable mobile enterprise applications project has in our opinion two weak spots: integration and security. The first because there's more than just one type of integration involved: one is the connection of new mobile app with the existing systems (integration capabilities between various mobile technologies) and the other concerns the correlation with the existing business processes that it will replace, impact, or improve. Security is perhaps the Achilles' heel, mainly because mobile devices are more exposed to malware and they enable new forms of attack. Ongoing efforts in achieving security are reported [17].

\section{Conclusions}

The notorious IT market research company IDC considers that the organizations should shift to "the third platform", which assembles mobility, big data, cloud computing and so- cial media and our research conclusion corroborates with this report. Moreover, IDC predicts that by 2020 , likely $60 \%$ of IT spending will be on cloud, social, mobility and big data technologies, with "thirdplatform" revenue projected to grow by $12 \%$ each year for the next seven years. By comparison, second platform spending - referring to client/server technologies - is only growing by about $1 \%$ year over year, according to the same source [18].

On the other hand, surveys among IT managers show a reluctance to move the business workflows to mobile devices - considering key applications such as ERP, CRM, and HR. Moreover, enterprise applications still aren't moving to the cloud. The applications that are mostly likely to move are those that are already safely in the cloud: email, mobile apps, collaboration and data backup [19].

Therefore, we consider that for the moment the mobile enterprise platform looks like in figure 6 and aims to a model based on a mobile middleware like in Figure 5. The ERP, CRM and other enterprise applications are still considered mission-critical systems, so they will probably remain on-premise or migrate to the private cloud. 


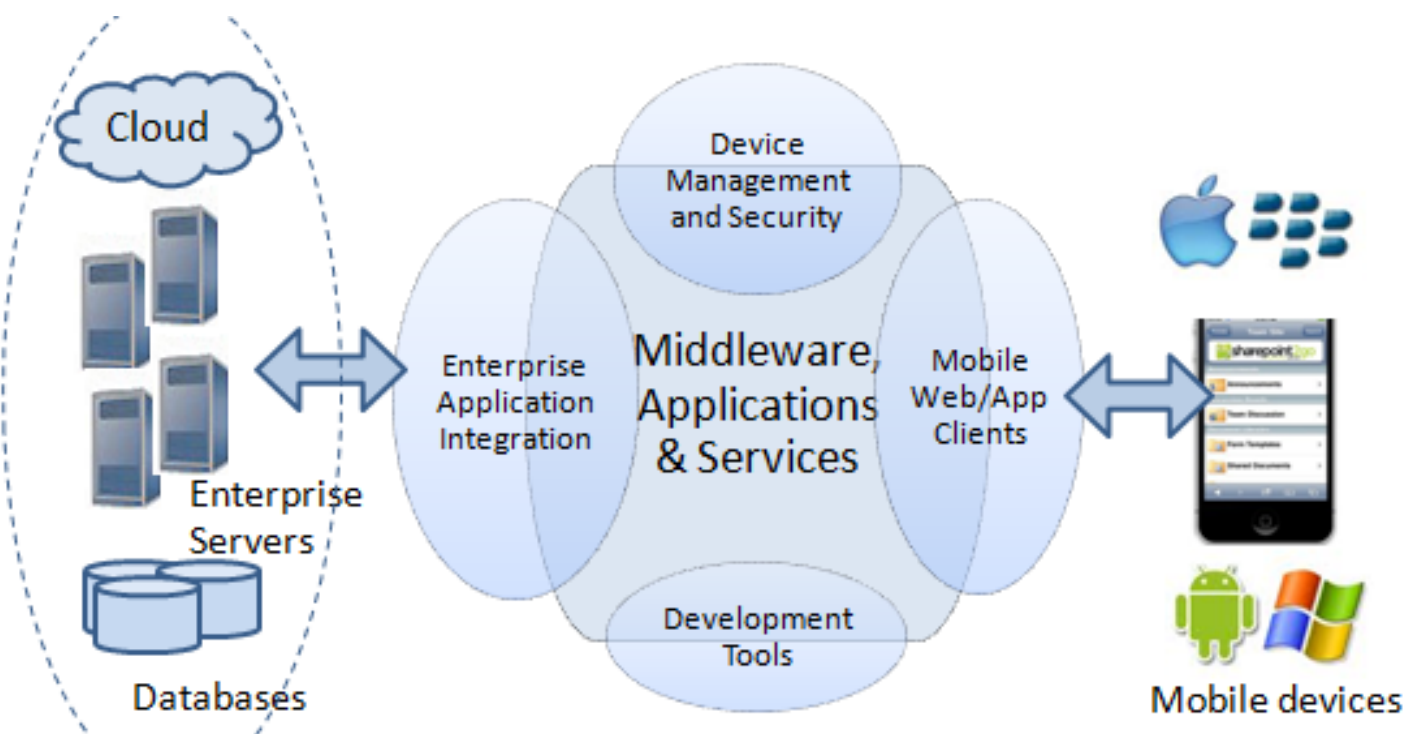

Fig. 6. The mobile enterprise platform

But in a world where mobile devices outsell PCs (in 2010 the Gartner Research group predicted that by 2013 mobile phones will overtake personal computers!) and where by 2015 over $80 \%$ of the handsets sold in mature markets will be smartphones [20], the mobile enterprise is on its way being supported by constant achievements such as:

- Improved security related to lost/stolen devices and insecure Wi-Fi;

- Enlargement of mobile management options: wrappers, containers, virtualization, mobile Software Development Kits (SDKs), mobile virtual private networks (mVPNs), Mobile Device Management (MDM), Mobile Application Management (MAM), and anti-malware;

- Development of the "app store" distribution model;

- Materialization of mobile middleware;

- Introduction of methodologies for implementing mobile projects.

The convergence of mobile, cloud, social, and big data into a single high-value IT delivery platform will produce effects like:

- Consumerized IT will be more and more involved in the mobile space;

- New opportunities to drive value from mobile technology;

- The information system that records will transform into a system of engagement;
- Mobile capabilities will become common in operations, commerce, collaboration, and marketing;

- Mobile middleware will support multiple platforms and back-end connectivity ;

- Development and integration of highquality mobile apps.

In the consumer space, mobile devices with mobile applications have an enormous popularity. Today, the personal mobile devices are brought at work, amplifying social networking within the company walls and giving interaction a context. The contextual information generates a massive volume of data that must be gathered and used in order to add value to the business processes and to better serve the customers and the employees. Companies must define a social approach for collecting, managing, protecting, inferring, and performing on the data gathered by means of social interaction through mobile devices.

The ubiquity of mobile technologies, the enthusiasm about social and the promise of the cloud have created new opportunities for enterprises to deliver applications that improve customers' service and employees' productivity and efficiency. Our further research intends to answer questions like: What makes some companies so much better at new mobile enterprise than others? What business trends are they seeing that others are not able to observe? How are they leveraging mobile, 
social and cloud technology? What unique process, application, and infrastructure capabilities are they developing?

\section{References}

[1] H. Nagy, Enabling Enterprise Transformation, Springer Publishing, 2010

[2] L. Herbert, "The Forrester Wave: Enterprise Mobility Services, Q1 2013" [online].

Available: http://www.forrester.com/pimages/rws/r eprints/document/87581/oid/1-LTEQDU

[3] P. Clarke, "Assessing the enterprise wireless LAN for the new mobile workforce" [online].

Available: http://searchnetworking.techtarget.com/f eature/Assessing-the-enterprise-wirelessLAN-for-the-new-mobile-workforce

[4] ***, "IT Shifts to Third Platform as Mobile Spend Grows by 20\%" [online]. Available:

http://mobileenterprise.edgl.com/news/I T-Shifts-to-Third-Platform-as-MobileSpend-Grows-by-20-83462

[5] ***, Handbook of Cloud Computing, Springer, 2010 [online]. Available: http://books.google.ro/books/about/Hand book_of_cloud_computing.html?id=jLN GCPs6rr4C\&redir_esc=y)

[6] http://scholar.google.ro/scholar? $\mathrm{q}=\% 22$ cloud+computing +security $\% 22 \&$ $\mathrm{hl}=\quad$ ro\&as_sdt $=0 \&$ as_vis $=1 \&$ oi $=$ scholart $\&$ sa $=X \&$ ei $=u$ Dl6UdLkLYn8OZy6gdgP\&ved=0CCkQ gQMwAA

[7] http://www.admobimedia.com/mobilemarketing/

[8] R. Pasqua and N. Elkin, Mobile Marketing: An Hour a Day, John Wiley \& Sons, 2012

[9] ***, "2011 Consumerization of IT Study" [online]. Available: http://idc.cycloneinteractive.net/unisysiview-2011/en/

[10] A.B. Munteanu, "Information security risk assessment: The qualitative versus quantitative dilemma", in Managing Information in the Digital Economy: Issues \& Solutions, 2006, pp. 227-232

[11] http://maps.yankeegroup.com/ygapp/ content/59785/55/SURVEYDATA/169

[12] D. Nicol, Mobile Strategy: How Your Company Can Win by Embracing Mobile Technologies, IBM Press, 2013

[13] http://www.appearnetworks.com/ learning-centre/mobile-platform-selection

[14] http://searchconsumerization.techtarget. com/definition/device-agnostic-deviceagnosticism

[15] D. Rowinski, "The Rise of Mobile Cloud Services: BaaS Startups Grow Up" [online]. Available: http://readwrite.com/2012/04/17/mobilebackend-as-a-service-ec

[16] O. Dospinescu, "E-Wallet. A New Technical Approach", Acta Universitatis Danubius. Economica, Vol. 8, No. 5, 2012, pp. 84-94 [online]. Available: http://journals.univ-

danubius.ro/index.php/oeconomica/articl e/view/1423

[17] C. Nachenberg, "A Window into Mobile Device Security" [online]. Available: http://www.symantec.com/content/en/us/ about/media/pdfs/symc_mobile_device_ security_june2011.pdf

[18] B. Cole and D. Essex, "Third platform of IT goes mainstream at IDC Directions 2013" [online]. Available: http://searchmanufacturingerp.techtarget. com/news/2240179619/Third-platformof-IT-goes-mainstream-at-IDC-

Directions-2013

[19] D. Essex, "Is IT really getting ready for a third platform?" [online]. Available: http://searchfinancialapplications.techtar get.com/news/2240180342/Is-IT-reallygetting-ready-for-a-third-platform

[20] http://www.mactech.com/2012/10/24/m obile-phones-overtake-computers-mostcommon-web-access-device 


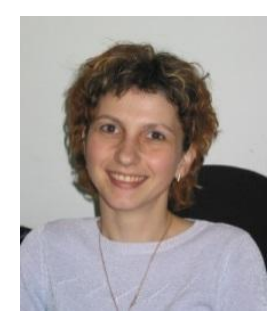

Luminiţa HURBEAN has graduated the Faculty of Economics at the "Al. I. Cuza" University of Iaşi in 1991. She holds a PhD diploma in Cybernetics and Economic Informatics from 1999 and she activated between 1991 and 2002 at the "Al. I. Cuza" University of Iaşi, where she became Assistant Professor in 2000. Currently she is Assistant Professor within the Department of Business Information Systems at the Faculty of Economics and Business Administration in the West University of Timişoara. She is the author of 14 books and over 80 articles in journals and conferences' proceedings in the field of enterprise information systems, ERP systems, IT projects management, and information technology driven change management. Her main research efforts concentrate on the ERP systems implementation.

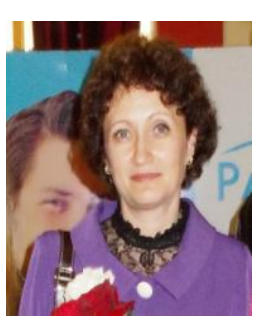

Doina FOTACHE has graduated the Faculty of Economics at the "Al. I. Cuza" University of Iaşi in 1989. She holds a PhD diploma in Accounting from 2000 and currently she is Professor within the Department of Business Information Systems at the Faculty of Economics and Business Administration in the Al. I. Cuza University of Iasi. She is the author of 12 books and over 90 articles in journals and conferences' proceedings in the field of enterprise information systems, ERP systems, CRM systems, and Collaborative software (groupware). 